\title{
INFLUENCE OF FLY ASH TYPE ON MECHANICAL PROPERTIES AND SELF-HEALING BEHAVIOR OF ENGINEERED CEMENTITIOUS COMPOSITE (ECC)
}

\author{
HUI MA ${ }^{1}$, SHUNZHI QIAN² AND VICTOR C. LI ${ }^{1 *}, 3$ \\ ${ }^{1}$ Southeast University \\ Nanjing, China \\ E-mail: huim@seu.edu.cn \\ ${ }^{2}$ Nanyang Technological University \\ Singapore \\ E-mail: $\underline{\text { SZQian@ @ ntu.edu.sg }}$ \\ ${ }^{3}$ Southeast University and University of Michigan \\ Nanjing, China and Ann Arbor, USA \\ E-mail: vcli@umich.edu
}

Key words: Engineered Cementitious Composite (ECC), fly ash type, mechanical properties, self-healing

\begin{abstract}
This paper aims to clarify the influence of different types of fly ash on the mechanical properties and self-healing behavior of Engineered Cementitious Composite (ECC). Five types of fly ash with different chemical and physical properties were used in ECC mixtures. The fly ash to cement ratio was fixed at 3.0. The compressive and uniaxial tensile tests were conducted to evaluate the influence of fly ash type on mechanical properties. The permeability test was used to assess self-healing behavior of ECCs with different types of fly ash. The microtopography and chemical characteristics of the self-healing products in the crack were observed and examined by scanning electron microscope (SEM) and energy dispersive X-ray spectroscopy (EDS). The fly ash with relatively higher calcium content and smaller particle size was found conducive to a higher compressive strength. The lower combined $\mathrm{Al}_{2} \mathrm{O}_{3}$ and $\mathrm{CaO}$ content of this fly ash, however, was found to enhance the tensile strain capacity. Furthermore, high calcium fly ash accelerates the self-healing process of ECC for the same pre-damaged level. The self-healing product was a mixed $\mathrm{CaCO}_{3} / \mathrm{C}-\mathrm{S}-\mathrm{H}$ system with the $\mathrm{CaCO}_{3}$ as the main ingredient.
\end{abstract}

\section{INTRODUCTION}

Engineered cementitious composites (ECC) developed by Li and coworkers [1] is a special kind of the high performance fiber reinforced cementitious composites (HPFRCC), which exhibits an excellent tensile strain hardening behavior. The compressive strength can reach 40-80 $\mathrm{MPa}$ with typical ECC mix proportions. A tensile strength of $5 \mathrm{MPa}$ and tensile strain capacity of 3-5\% (300-500 times that of concrete or FRC) have been demonstrated in ECC materials. The excellent tensile ductility is achieved with the formation of multiple cracks, and the crack width can be 
controlled at around $60 \mu \mathrm{m}$. Benefitting from such advantages, ECC materials have been successfully applied on high rise building, dam repair [2], bridge deck link slab [3], etc.

Different from conventional concrete, ECC materials are mixed without large aggregates in order to improve the workability and the dispersion of fiber, and more essentially, control matrix toughness for strain hardening behavior [4]. However, relatively high cement content in ECC not only results in high hydration heat, high shrinkage and high material cost, but also increases the emission of greenhouse gases [5]. One natural method to address these problems is to replace cement by fly ash in ECC materials. Fly ash is a by-product of coal burning power plants and usually considered as a waste material. With its pozzolanic properties, fly ash has been widely used as a raw material in concrete. Statistics compiled by the American Coal Ash Association (ACAA) show that 50.42 million tons of fly ash were produced in the United States in 2014 , while only 13.13 million tons were used for manufacturing cement/concrete products, and other 10 million tons were used in other fields, such as road base and embankments [6]. This suggests that significant researches still need to be done to improve their usage in concrete.

Although incorporation of fly ash in ECC has been investigated by a number of researchers [4][7], very few studies have been conducted on the influence of fly ash quality/type on ECC's properties. It is well known that fly ash from different sources may have different chemical compositions and reactivity. Furthermore, altering of fly ash source can significantly affect ECC's properties in most cases. Therefore, in this study, five different types of fly ash were screened to investigate their influence on ECC's properties. To be more specific, the mechanical properties (compression and tension) of ECCs and the self-healing behavior of pre-cracked ECCs with different fly ashes were examined. The research details are given in the following sections.

\section{EXPERIMENTAL PROGRAMS}

\subsection{Materials and mixture proportions}

The ordinary Portland cement (PII 42.5R cement [8]) and fly ashes (Type I [9]) conforming to Chinese national standards were used in this study. Five different types of fly ash from different coal-fired power plants were adopted to investigate their influence on ECC's mechanical properties and self-healing behavior. The chemical compositions and the grain size distribution of these fly ashes are shown in Table 1 and Figure 1, respectively. The fine silica sand with a range of 106-212 $\mu \mathrm{m}$ has a mean diameter of $150 \mu \mathrm{m}$. In order to obtain proper workability and good fiber dispersion, the polycarboxylate-based high range water reducing admixture (HRWRA) was used. PVA fiber with length of $12 \mathrm{~mm}$ and diameter of 39 $\mu \mathrm{m}$, produced by Kuraray Co. Ltd in Japan, was included in this research. The elastic modulus and tenacity of fiber is $42.8 \mathrm{GPa}$ and $1620 \mathrm{MPa}$, respectively. In order to reduce the interface bond of fiber and matrix, the PVA fiber has a surface oil coating of $1.2 \%$ by weight.

In order to highlight the influence of fly ash on ECC, relative high fly ash content (FA/C $=3.0$ ) was adopted in this study. The mix proportions of ECC mixtures with different fly ashes are listed in Table 2. In this table, the content of PVA fiber is by volume of whole ECC mixture.

Table 1: Chemical and physical properties of different fly ashes $(\%)$.

\begin{tabular}{|c|c|c|c|c|c|}
\hline $\begin{array}{c}\text { Fly ash } \\
\text { No. }\end{array}$ & $\mathrm{SiO}_{2}$ & $\mathrm{Al}_{2} \mathrm{O}_{3}$ & $\mathrm{Fe}_{2} \mathrm{O}_{3}$ & $\mathrm{CaO}$ & $\begin{array}{c}\text { Loss on } \\
\text { ignition }\end{array}$ \\
\hline A & 54.3 & 36.0 & 2.6 & 1.7 & 1.5 \\
\hline
\end{tabular}




\begin{tabular}{|c|c|c|c|c|c|}
\hline $\mathrm{B}$ & 50.5 & 17.8 & 7.4 & 4.3 & 2.4 \\
\hline $\mathrm{C}$ & 56.2 & 31.4 & 3.9 & 2.8 & 2.1 \\
\hline $\mathrm{D}$ & 47.5 & 24.9 & 5.7 & 4.2 & 2.2 \\
\hline $\mathrm{E}$ & 54.2 & 22.6 & 7.2 & 8.6 & 1.4 \\
\hline
\end{tabular}

Table 2: Mixture proportions of ECCs (by weight except fiber by volume).

\begin{tabular}{|c|c|c|c|c|c|c|}
\hline & C & S & FA & W & $\begin{array}{c}\text { HRW } \\
\text { RA }\end{array}$ & $\begin{array}{c}\text { PVA } \\
\text { fiber }\end{array}$ \\
\hline M1 & 1 & 1.45 & 3.0 (FA A) & 1 & 0.03 & $2 \%$ \\
\hline M2 & 1 & 1.45 & 3.0 (FA B) & 1 & 0.03 & $2 \%$ \\
\hline M3 & 1 & 1.45 & 3.0 (FA C) & 1 & 0.03 & $2 \%$ \\
\hline M4 & 1 & 1.45 & 3.0 (FA D) & 1 & 0.03 & $2 \%$ \\
\hline M5 & 1 & 1.45 & 3.0 (FA E) & 1 & 0.03 & $2 \%$ \\
\hline
\end{tabular}

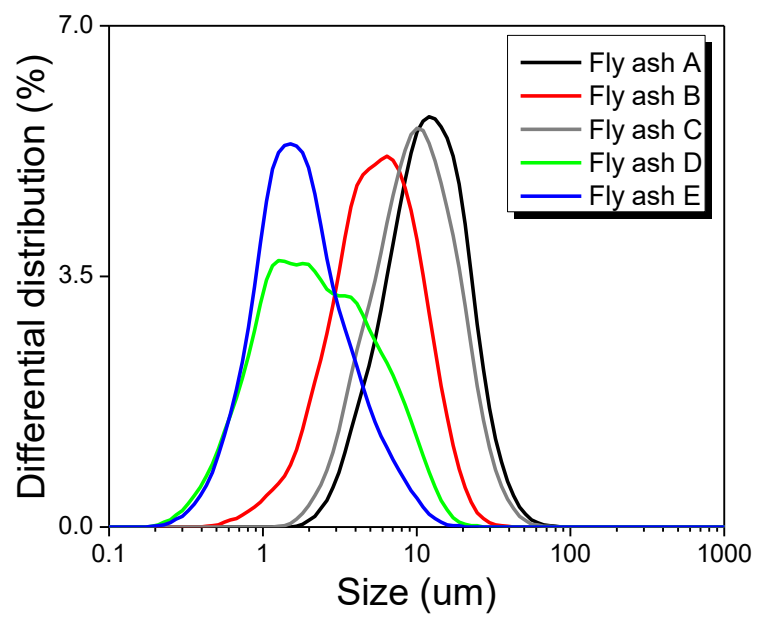

Figure 1: The grain size distributions of different fly ashes.

\subsection{Specimens preparation and experimental program}

All ECC mixtures were prepared using a planetary mixer with $10 \mathrm{~L}$ capacity. All solid ingredients, including cement, silica sand and fly ash, were first mixed for 3 minutes. Then water and HRWRA were added and mixed for 5 minutes. When the fresh mortar reached a uniform state, the PVA fibers were added slowly and mixed for 10 more minutes until the fibers were evenly distributed. All specimens were de-molded after $24 \mathrm{~h}$, and then cured under sealed condition at $95 \pm 5 \% \mathrm{RH}$ and temperature of $20 \pm 2{ }^{\circ} \mathrm{C}$ until the predetermined testing age of 28 days.

The mechanical properties of ECC mixtures under compression and tension were investigated in this study. For each ECC mixture, three cube specimens with size of $75 \times$ $75 \times 75 \mathrm{~mm}^{3}$ were prepared for compressive test. The tensile properties of ECCs were investigated by uniaxial tensile test. The tensile setup and the geometry of specimen are shown in Figure 2. Two LVDTs were fixed on both sides of the specimen to measure the deformation, and the test was conducted under displacement control of $0.5 \mathrm{~mm} / \mathrm{min}$ as recommended by the Japan Society of Civil Engineers (JSCE) [10].

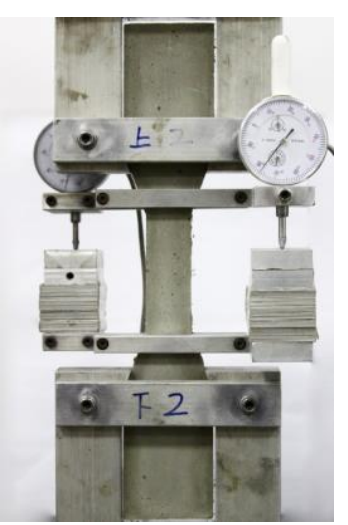

(a)

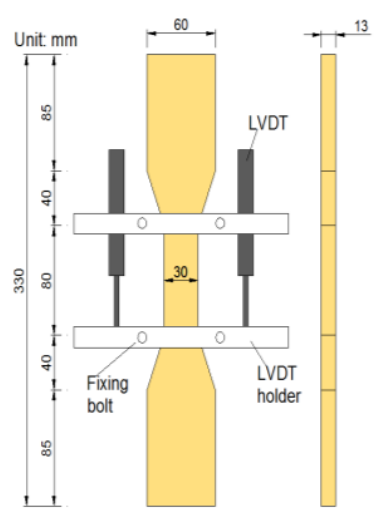

(b)
Figure 2: The uniaxial tensile test: (a) test setup and (b) specimen dimension.

Permeability test was conducted to evaluate the self-healing behavior of pre-cracked ECCs with different fly ashes. The specimens with a diameter of $100 \mathrm{~mm}$ and a height of $20 \mathrm{~mm}$ were prepared. The initial cracks in specimen were introduced via splitting test, as shown in Figure 3. After cracking, three to five specimens with the same crack patterns (crack number and crack width) 
were selected in permeability test for each ECC mixture. The weight of water penetrated through the cracked ECC specimen was measured for one hour using the setup shown in Figure 4. This test results served as the initial value of pre-cracked ECCs without self-healing, and then the specimens were cured in the condition of wet/dry cycle (cured in the $20^{\circ} \mathrm{C}$ water for $24 \mathrm{~h}$ and then in the room air at $20 \pm$ $1^{\circ} \mathrm{C}$ and $50 \pm 5 \% \mathrm{RH}$ for $24 \mathrm{~h}$ ). The weight of water penetrated through the specimen was measured after each curing cycle until no penetration of water.

Cubic specimens with dimensions of $5 \times 5$ $\times 5 \mathrm{~mm}^{3}$, containing one crack of $50 \mu \mathrm{m}$ wide were cut off from tensile specimens, and then cured in the condition of wet/dry cycle. After ten curing cycles, the morphology and chemical characteristics of self-healing products in the crack were investigated by environment scanning electron microscope (ESEM) and energy dispersive X-ray spectroscopy (EDS).

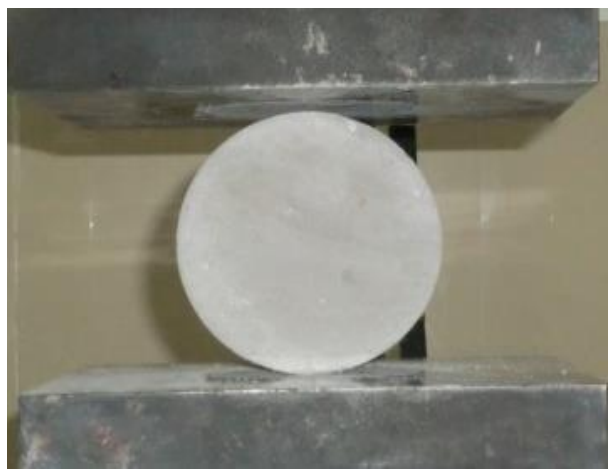

Figure 3: Pre-cracking ECC by splitting test.

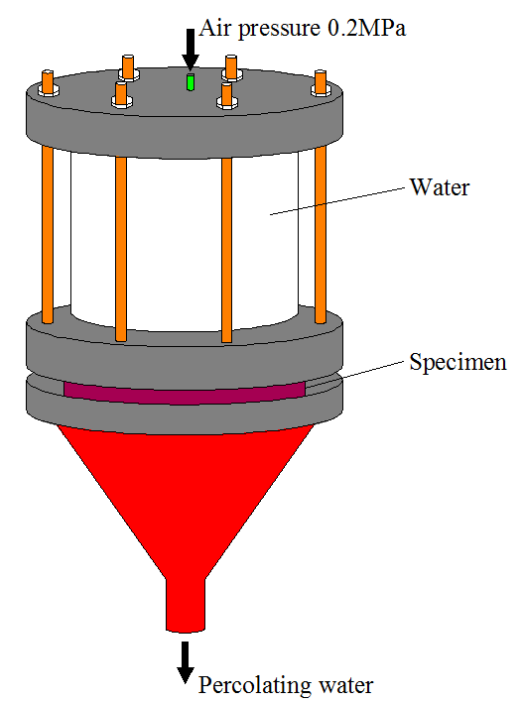

Figure 4: Permeability test setup.

\section{RESULTS AND DISCUSSIONS}

\subsection{Influence of fly ash type on mechanical properties of ECCs}

The compressive strengths of ECCs with different fly ashes are shown in Figure 5. As can be seen in this figure, M1 has the lowest compressive strength of $17 \mathrm{MPa}$, while M5 has the highest compressive strength of $38 \mathrm{MPa}$. It indicates that fly ash E contributes much more to strength gain in ECC than fly ash A. According to Mehta [11], the fly ash with high calcium content has a superior reactivity compared to the low calcium fly ash probably due to both the presence of reactive crystalline compounds such as $\mathrm{C}_{3} \mathrm{~A}$ and more active calcium aluminosilicate glass. In this study, the $\mathrm{CaO}$ content of fly ash $\mathrm{E}$ is $8.6 \%$ and much larger than that of fly ash A (1.7\%), which results in highest compressive strength for M5. When comparing all ECCs, the compressive strength is largely consistent with the $\mathrm{CaO}$ content in fly ash, except for ECCs M2 and M4. Although the $\mathrm{CaO}$ content of fly ash $\mathrm{B}$ is slightly larger than that of fly ash $\mathrm{D}$, the compressive strength of M2 is smaller than that of M4. In addition to the calcium content, the particle size distribution is also an important parameter governing the reactivity of fly ash 
[11]. The reactivity is found to be directly proportional to the amount of small particles. As can be seen in Figure 1, the fly ash D has smaller particles than that of fly ash B, therefore the compressive strength of ECC M4 is larger than that of M2.

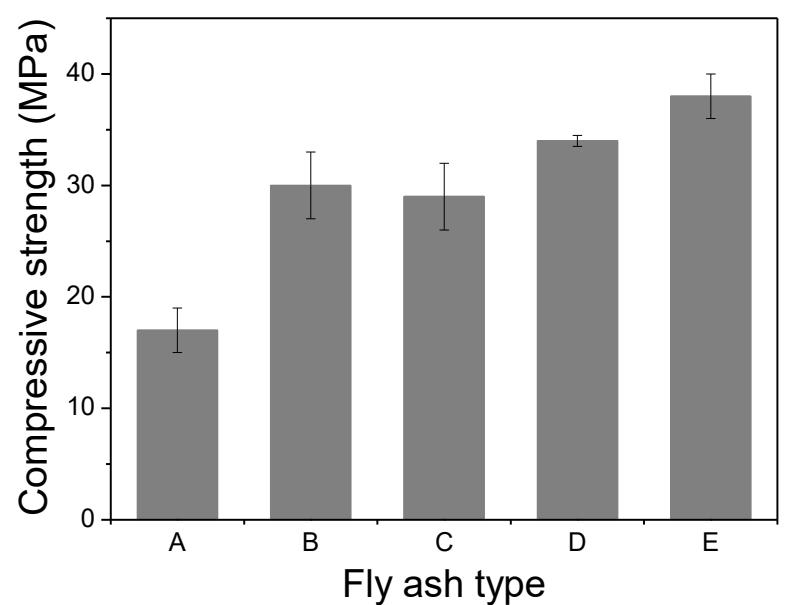

Figure 5: Compressive strength of ECCs with different fly ash.

The uniaxial tensile curves of ECCs are shown in Figure 6. As can be seen in this figure, ECCs (M1 and M3) exhibit smaller tensile strain capacity compared to other three ECCs. According to Wang and $\mathrm{Li}$ [4], the chemical bond $\mathrm{G}_{\mathrm{d}}$ of the interface between PVA fiber and cementitious matrix is governed by the metal cation concentration, in particular $\mathrm{Al}^{3+}$ and $\mathrm{Ca}^{2+}$. For PVA polymer bound calcium aluminate cement $\left(\mathrm{C}_{3} \mathrm{~A}\right)$, it was found that $\mathrm{Al}^{3+}$ and $\mathrm{Ca}^{2+}$ are responsible for the formation of a strong thin layer interface between cement grain and PVA bulk polymer [12][13]. In fact, the $\mathrm{Ca}(\mathrm{OH})_{2}$ crystal on the PVA fiber surface was observed in ECC [14][15]. In addition, the $\mathrm{Al}_{2} \mathrm{O}_{3}$ in fly ash can react with $\mathrm{Ca}(\mathrm{OH})_{2}$ to form calcium aluminate hydrates (Pozzolanic reaction). Hence, the fly ash with higher combined $\mathrm{Al}^{3+}$ and $\mathrm{Ca}^{2+}$ content, e.g. fly ash $\mathrm{A}$ and fly ash $\mathrm{C}$, can lead to a larger $\mathrm{G}_{\mathrm{d}}$. According to the ECC design theory, the complementary energy $\mathrm{J}_{\mathrm{b}}$ ' can be calculated as Formula 1:

$$
J_{b}^{\prime}=V_{f} \frac{L_{f}}{d_{f}}\left(\frac{\tau_{0}^{2} L_{f}^{2}}{6 d_{f} E_{f}}-2 G_{d}\right)
$$

where $\mathrm{V}_{\mathrm{f}}$ is the volume content of PVA fiber; $\mathrm{Lf}_{\mathrm{f}}$, $\mathrm{d}_{\mathrm{f}}$ and $E_{\mathrm{f}}$ is the length, diameter and elasticity modulus of PVA fiber, respectively; $\tau_{0}$ and $G_{d}$ is the frictional bond and chemical bond of interface between fiber and matrix, respectively.

The larger $G_{d}$ can lead to a smaller $J_{b}$ '. The energy criterion, as shown in Formula 2, of ECC design cannot be met satisfactorily, which results in a poor tensile strain hardening behavior, in particular, a smaller tensile strain capacity.

$$
J_{b}^{\prime}>J_{t i p}
$$

where $\mathrm{J}_{\text {tip }}$ is the crack tip toughness of matrix.

Interface frictional bond $\tau_{0}$ is closely related to the compactness and toughness of interfacial transition zone (ITZ) between fiber and matrix. According to literatures [7][16], the un-hydrated fly ash with small particle size increases the packing density of ITZ, which can increase the $\tau_{0}$. Therefore, the larger particle size of fly ash $\mathrm{A}$ and $\mathrm{C}$ leads to smaller $\tau_{0}$, which also results in smaller $\mathrm{J}_{\mathrm{b}}$ ' and smaller tensile strain capacity of ECCs M1 and M3. On the contrary, the ECCs M2, M4 and M5 exhibit an excellent tensile strain capacity of $5 \%$, as shown in Figure 6, due to the lower combined $\mathrm{Al}^{3+}$ and $\mathrm{Ca}^{2+}$ content and smaller particle size of fly ashes B, D and E, which is consistent with above discussions.

As can be seen in Figure 6, the ECCs M1 and M3 also exhibit smaller ultimate tensile strength, in particular, the ultimate tensile strength of M1 is only $3 \mathrm{MPa}$. Leng and $\mathrm{Li}$ [17] showed that the fiber bridging capacity $\sigma_{0}$ and $\tau_{0}$ are positive linearly related, and can be calculated as Formula 3, which ignores fiber rupture, slip-hardening, and snubbing effect for simplicity.

$$
\sigma_{0}=\frac{4 V_{f} \tau_{0}}{L_{f} d_{f}}\left(\frac{L_{f}}{2}\right)^{2} \cdot \eta_{B}
$$

where the $\eta_{в}$ is defined as the efficiency of 
fiber bridging [18], and the value of $\eta_{\mathrm{B}}$ is $2 / \pi$ and $1 / 2$ in the case of $2 \mathrm{D}$ and $3 \mathrm{D}$ distribution of fiber, respectively [19].

The fiber bridging capacity is consistent with ultimate tensile strength. Therefore, the fly ash with larger particle size, e.g. fly ash A and fly ash $\mathrm{C}$, leads to the smaller $\tau_{0}$, and then results in a smaller fiber bridging capacity and therefore ultimate tensile strength of ECC.

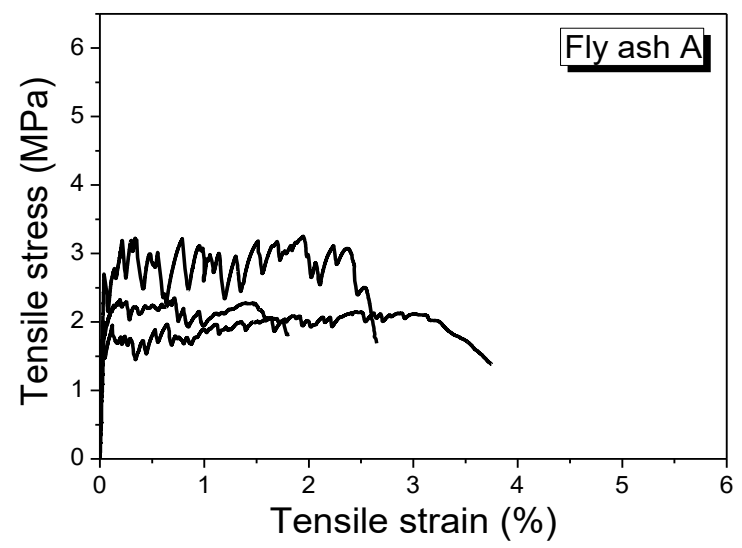

(a)

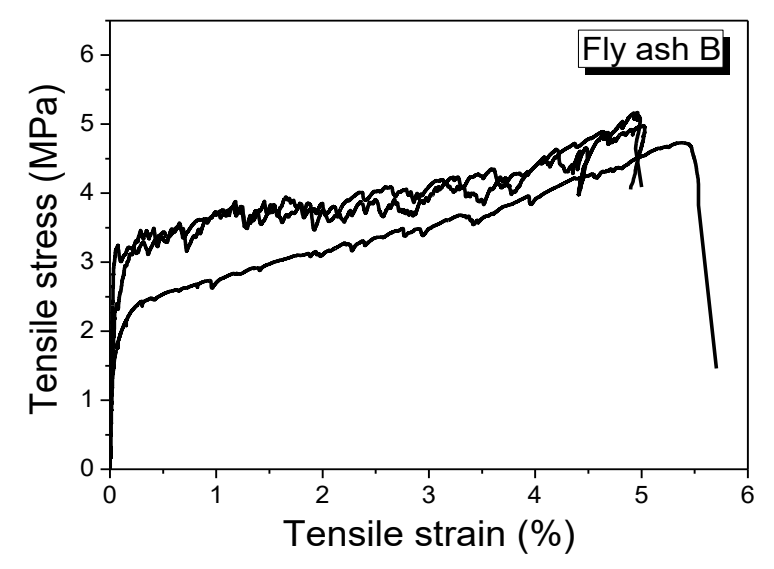

(b)

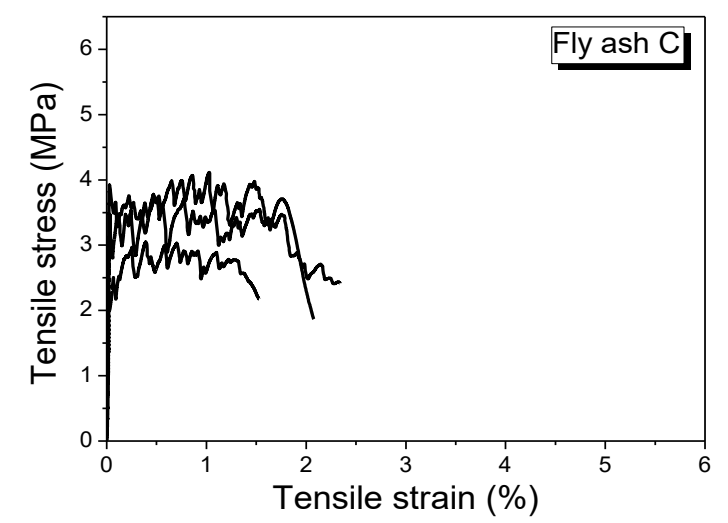

(c)

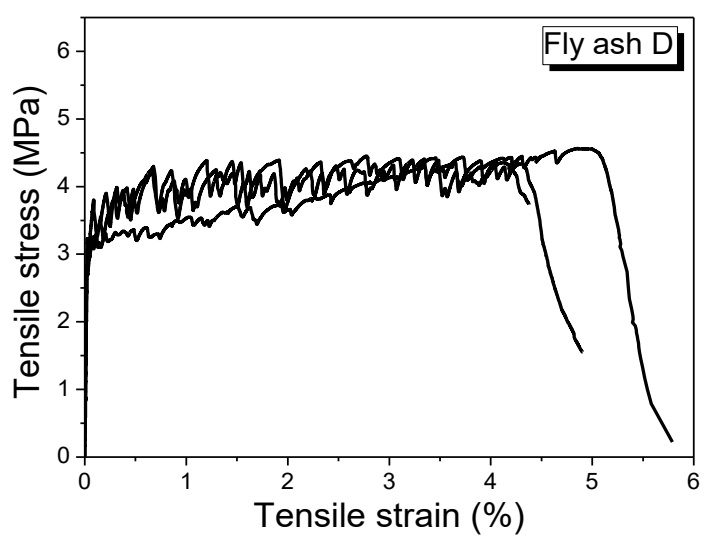

(d)

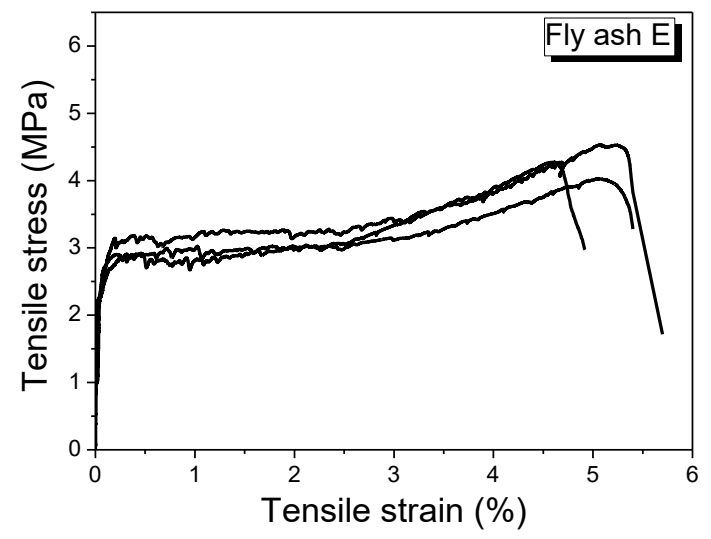

(e)

Figure 6: Uniaxial tensile stress-strain curves of ECCs with different fly ash.

The crack patterns, including crack number and crack width, of ECCs are shown in Figure 7. As can be seen in this figure, ECC M1 has the least cracks and largest crack width. ECC M3 also has a lesser crack and larger crack width. According to $\mathrm{Wu}$ and $\mathrm{Li}$ [20], the theoretical crack spacing $\mathrm{Xd}_{\mathrm{d}}$ can be calculated from Formula 4:

$$
x_{d}=\frac{L_{f}-\sqrt{L_{f}^{2}-2 \pi L_{f} \lambda x^{\prime}}}{2}
$$

where $\lambda=\frac{2}{\pi} \frac{4+f^{2}}{e^{\pi f / 2}+1}=\frac{4}{\pi g}, \mathrm{~g}$ is the snubbing factor $\mathrm{g}=2 \frac{e^{\pi f / 2}+1}{4+f^{2}}$, and $\mathrm{f}$ is the snubbing coefficient; the $\mathrm{x}$ ' is defined as Formula 5:

$$
x^{\prime}=\frac{E_{m} V_{m}}{V_{f}} \frac{\varepsilon_{m u} r_{f}}{2 \tau_{e f f}}=\frac{V_{m}}{V_{f}} \frac{\sigma_{m u} r_{f}}{2 \tau_{e f f}}
$$

where $\mathrm{E}_{\mathrm{m}}$ is the matrix modulus; $\mathrm{V}_{\mathrm{f}}$ and $\mathrm{V}_{\mathrm{m}}$ are 
the volume fraction of fiber and matrix, respectively; $\varepsilon_{\mathrm{mu}}$ and $\sigma_{\mathrm{mu}}$ are the matrix failure strain and stress; $\mathrm{r}_{\mathrm{f}}$ is the fiber radius; $\tau_{\text {eff }}$ is the effective interfacial bond strength.

Combining these formulas, the crack spacing can be obtained as Formula 6:

$$
x_{d}=\frac{L_{f}-\sqrt{L_{f}^{2}-4 \sigma_{m u} L_{f} V_{m} r_{f} / g \tau_{e f f} V_{f}}}{2}
$$

The crack spacing is negatively related with frictional bond strength. Therefore, smaller frictional bonds of ECCs M1 and M3 lead to larger crack spacing, which means less cracks. In addition, lower $\tau_{0}$ indicates a weak holding load in the interface and easy sliding of fiber, which results in larger crack width for ECC M1 and M3.

The most cracks and smallest crack width were observed in ECC M2, although the fly ash $\mathrm{B}$ has a larger particle size than fly ash D and E. This may be explained that the excessive $\tau_{0}$ can cause the rupture of fibers and then reduce the effective interfacial bond strength, which results in larger crack spacing and lesser cracks. Furthermore, the reduction of effective interfacial bond strength may lead to larger crack width.

Based on the above discussions, during the raw material screening of ECC design, the fly ash with higher calcium content and smaller particle size should be selected for high compressive strength. However, the fly ash with lower combined $\mathrm{Al}_{2} \mathrm{O}_{3}$ and $\mathrm{CaO}$ content should be selected in order to obtain an excellent tensile strain capacity.

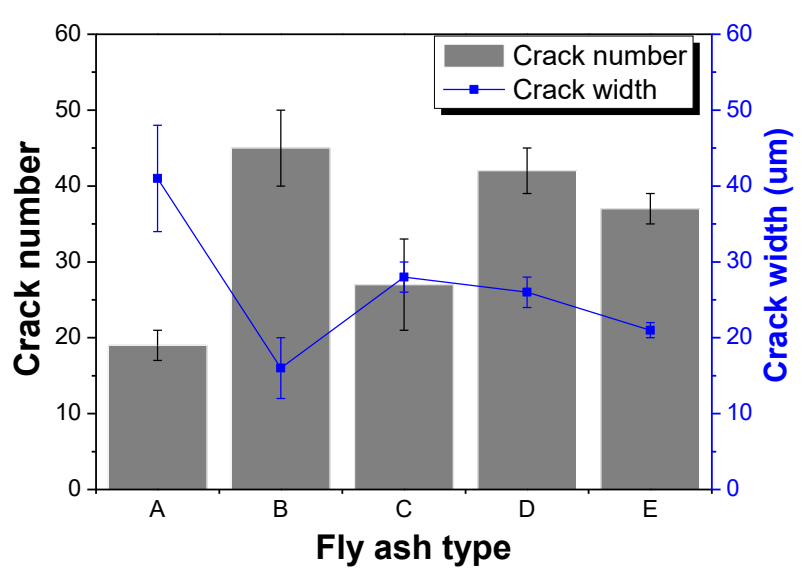

Figure 7: The crack patterns of ECCs with different type fly ash.

\subsection{Influence of fly ash type on self-healing of ECCs}

The results of permeability test are shown in Figure 8. The figure shows the change of relative permeability with curing cycle due to self-healing process in pre-cracked ECCs. The permeability after each cycle was normalized by the original value from the unhealed specimens immediately after pre-cracking. As can be seen in this figure, generally more gentle descending slopes for ECCs can be clearly observed after the second curing cycle. The mechanisms of self-healing in ECC are further hydration of the unreacted cementitious materials, the sediment of crystallization calcium carbonate and the filling by the impurities in the water and concrete particles [21][22][23]. In the early stage of ECC's self-healing, the further hydration of unreacted cement is the main mechanism, and self-healing product is mainly C-S-H [24]. The sediment of crystallization calcium carbonate is the main mechanism for self-healing of mature cementitious materials [25]. These two stages have different healing speeds, which may result in the different slopes before and after second cycle in Figure 8. In addition, the same type and content of cement was adopted for different ECCs, which may explain very similar 
descending curves for different ECCs in the first 2 cycles.

Furthermore, M5 descends most rapidly after the second cycle, which indicates that ECC M5 has the fastest speed of self-healing compared to other ECCs. On the other hand, M1 has the slowest descending rate while M2, M3 and M4 have very similar moderate reduction rate. The sediment of calcium carbonate during self-healing was mainly obtained from the reaction: $\mathrm{Ca}(\mathrm{OH})_{2}+\mathrm{CO}_{2}+$ $\mathrm{H}_{2} \mathrm{O}=\mathrm{CaCO}_{3}+2 \mathrm{H}_{2} \mathrm{O}$. The $\mathrm{Ca}(\mathrm{OH})_{2}$ is mainly from the hydration products of cement. In addition, the $\mathrm{CaO}$ from fly ash can react with $\mathrm{H}_{2} \mathrm{O}$ to form $\mathrm{Ca}(\mathrm{OH})_{2}$, and subsequently form $\mathrm{CaCO}_{3}$. Therefore the fly ash $\mathrm{E}$ with high $\mathrm{CaO}$ content can provide more $\mathrm{CaCO}_{3}$ during self-healing, which results in the fastest self-healing of ECC M5. The ECC M1 with lowest calcium content fly ash A exhibits the slowest self-healing rate.

The micro-topography of the healed crack in ECC is show in Figure 9(a), and the chemical element analysis of self-healing products is show in Figure 9 (b). As observed in Figure 9(a), the crack was filled with visible self-healing products. The chemical element analysis shows that the $\mathrm{Ca}, \mathrm{C}$ and $\mathrm{O}$ are the major elements for self-healing products (Figure 9(b)), while the elements of Si and $\mathrm{Al}$ occupy a small proportion. It indicates that the self-healing products of ECC consist of mostly $\mathrm{CaCO}_{3}$ and a small amount of C-S-H. There is no pronounced difference in chemical element analysis for ECCs with different types of fly ash and only one representative diagram is shown in Figure 9(b). As the specimens need to be coated by platinum before EDS test, the element $\mathrm{Pt}$ appears in the figure.

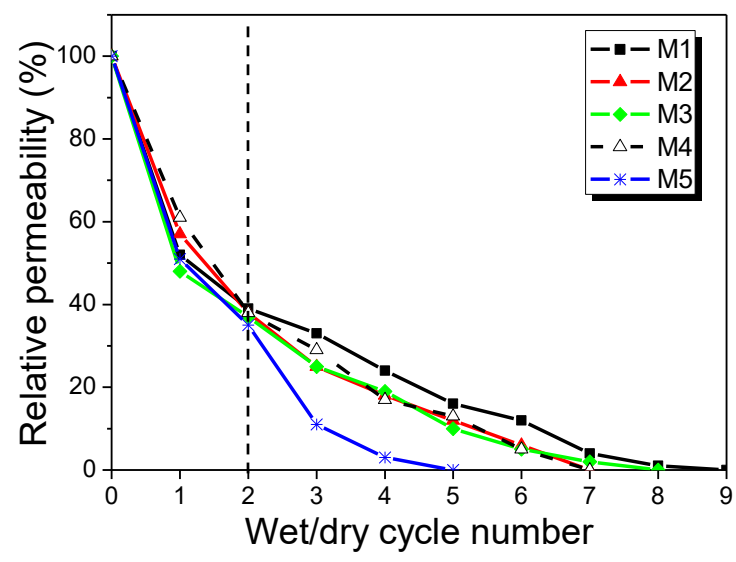

Figure 8: Relative permeability decreases with curing cycle for pre-cracked ECCs due to self-healing.

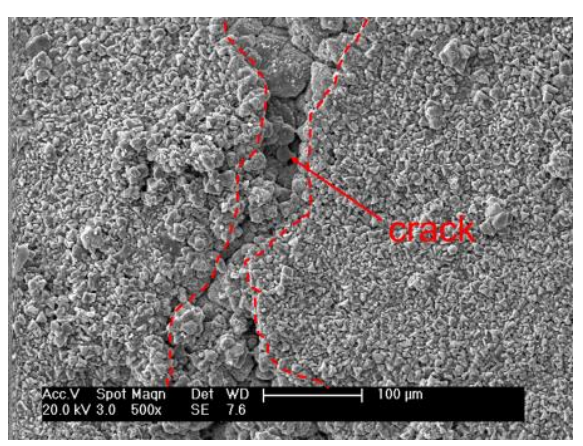

(a)

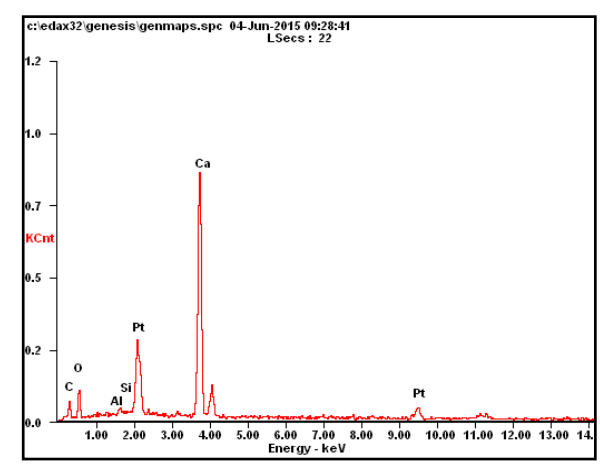

(b)

Figure 9: The micro-topography of healed crack (a) and chemical element analysis of self-healing products (b).

\section{CONCLUSIONS}

This research focuses on the influence of fly ash type on ECC's mechanical properties (compression and tension) and self-healing behavior. Five different types of fly ash were screened in this study. The specific conclusions can be drawn as follows: 
1. The fly ash with high calcium and small particle size is beneficial for the compressive strength of ECC.

2. The fly ash with lower combined $\mathrm{Al}_{2} \mathrm{O}_{3}$ and $\mathrm{CaO}$ content can reduce the chemical bond $\mathrm{G}_{\mathrm{d}}$, which is favorable for high tensile strain capacity.

3. Fly ash with small particle size leads to a large interfacial friction bond $\tau_{0}$ and larger fiber bridging capacity, which may result in a high ultimate tensile strength. However, excessive $\tau_{0}$ can lead to the premature rupture of fibers. Therefore fly ash with a moderate particle size may be adopted for high ultimate tensile strength.

4. The fly ash with high calcium can provide more crystallization calcium carbonate which is main contributor for self-healing at later stage. Therefore, the high calcium fly ash can improve the self-healing speed of crack in ECC at later stage.

5. The self-healing products of ECC consist of large amount of $\mathrm{CaCO}_{3}$ and small amount of C-S-H.

\section{REFERENCES}

[1] Li, V.C. 1993. From Micromechanics to Structural Engineering - The Design of Cementitious Composites for Civil Engineering Application. Journal of Structural Engineering and Earthquake Engineering, JSCE 10(2): 37-48.

[2] Rokugo, K., Kand, T., Yokot, H., and Sakata, N. 2009. Applications and Recommendations of High Performance Fiber Reinforced Cement Composites with Multiple Fine Cracking (HPFRCC) in Japan. Materials and Structures 42: 1197-1208.

[ 3 ] Lepech, M.D., and Li, V.C. 2009. Application of ECC for Bridge Deck Link Slabs. Materials and Structures 42: 1185-1195.
[4] Wang, S., and Li, V.C. 2007. Engineered Cementitious Composites with High-Volume Fly Ash. ACI Materials Journal 104: 233-241.

[5] Battelle. 2002. Climate Change toward a Sustainable Cement Industry, World Business Council on Sustainable Development (WBCSD): 92.

[6]https://www.acaa-usa.org/Portals/9/Files/PD Fs/2014ReportFinal.pdf

[7] Yang, E., Yang, Y., and Li, V.C. 2007. Use of High Volumes of Fly Ash to Improve ECC Mechanical Properties and Material Greenness. ACI Materials Journal 104: 303-311.

[ 8 ] GB175-2007, National Standard on Ordinary Portland Cement. 2007. (in Chinese)

[9] GB1596-88, National Standard on Fly Ash Used in Cement and Concrete. 1988. (in Chinese)

[10] JSCE. 2008. Recommendations for Design and Construction of High Performance Fiber Reinforced Cement Composites with Multiple Fine Cracks. Tokyo: Japan Soc. of Civil Engineers.

[11] Mehta, P.K. 1985. Influence of Fly Ash Characteristics on The Strength of Portland-Fly Ash Mixtures. Cement and Concrete Research 15: 669-674.

[12] Gulgun, M.A., Kriven, W.M., Tan, L.S., and McHugh, A.J. 1995. Evolution of Mechano-Chemistry and Microstructure of a Calcium Aluminate-Polymer Composite: Part I-Mixing Time Effects. Journal of Materials Research 10(7): 1746-1755.

[13] Rodger, S.A., Brooks, S.A., Sinclair, W., Groves, G.W., and Double, D.D. 1985. High Strength Cement Pastes. Journal of Materials Science 20: 2853-2860.

[14] Horikoshi, T., Ogawa, A., Saito, T., and Hoshiro, H. 2005. Properties of Polyvinylalcohol Fiber as Reinforcing Materials for Cementitious Composites. Proceedings of International RILEM Workshop 
on HPFRCC in Structural Applications, Honolulu, HI.

[15] Chan, Y. W., 1994. Fiber/Cement Bond Property Modification in Relation to Interfacial Microstructure. Department of Civil and Environmental Engineering, University of Michigan: Ann Arbor, MI.

[16] Kayali, O. 2004. Effect of High Volume Fly Ash on Mechanical Properties of Fiber Reinforced Concrete. Materials and Structures 37(269): 318-327.

[ 17 ] Li, V.C. and Leng, C.K.Y. 1992. Steady-State and Multiple Cracking of Short Random Fiber Composites. Journal of Engineering Mechanics 118: 2246-2264.

[18] Yang, E.H., Wang, S., Yang, Y., and Li, V.C. 2008. Fiber-Bridging Constitutive Law of Engineered Cementitious Composites. Journal of Advanced Concrete Technology 6(1):181-193.

[19] Wang, Y., Backer, S., and Li, V.C. 1990. A Statistical Tensile Model of Fiber Reinforced Cementitious Composites. Journal of Composites 20(3): 265-274.

[20] Wu, H.C., and Li, V.C. 1992. Snubbing and Bundling Effects on Multiple Crack Spacing of Discontinuous Random Fiber-Reinforced Brittle Matrix Composites. Journal of the American Ceramics Society 75(12): 3487-3489.

[21] Edvardsen, C. 1999. Water Permeability and Autogenous Healing of Cracks in Concrete. ACI Materials Journal 96: 448-455.

[ 22 ] Ramm, W., Biscoping, M. 1998. Autogenous Healing and Reinforcement Corrosion of Waterpenetrated Separation Cracks in Reinforced Concrete. Journal of Nuclear Engineering and Design 179: 191-200. [23 ] Reinhardt, H., and Joos, M. 2003. Permeability and Self-Healing of Cracked Concrete as a Function of Temperature and Crack Width. Journal of Cement and Concrete Research 33: 981-985.
[24] Ma, H., Qian, S., and Zhang Z. 2014. Effect of Self-Healing on Water Permeability and Mechanical Property of Medium-Early-Strength Engineered Cementitious Composites. Construction and Building Materials 68: 92-101.

[25] Schiessl, P., and Brauer, N. 1996. Influence of Autogenous Healing of Cracks on Corrosion of Reinforcement. Durability of Building Materials and Compoments 71: 542-552. 